\title{
0 conceito moderno de sociedade civil: do jusnaturalismo à economia política
}

The modern concept of civil society. From jusnaturalism to political economy

\section{Leonardo André Paes Müller Universidade de São Paulo}

\section{RESUMO}

Partindo da teoria da eticidade de Hegel, onde a sociedade civil é apresentada como o momento intermediário entre a família e local privilegiado da sociabilidade própria ao sujeito de direitos (pessoa), o presente artigo explora o modo como os três momentos da sociedade civil (sistema de satisfação de carências, administração da justiça e polícia) foram teorizados ao longo da segunda metade do século XviıI pela então nascente economia política, compreendida aqui como um desdobramento da moderna teoria do direito natural. Paralelamente, investiga-se o modo como, nesse mesmo período, o termo sociedade civil começa a ser empregado por economistas com um significado diferente do tradicional e até então vigente (onde sociedade civil é sinônimo de Estado), designando uma esfera organizada a redor de princípios não políticos e cuja análise exige um novo aparato conceitual.

\section{PALAVRAS-CHAVE}

Sociedade civil, Jusnaturalismo, Economia política, Carência, Justiça, Polícia.

\begin{abstract}
Hegel's Philosophy of Right presents civil society as the intermediate moment between family and State and as the privileged place of a peculiar kind of sociability connected with the subject of rights (person). The present paper explores how the three moments of Hegel's civil society (the system of needs, the administration of justice and the police) were conceived in the second half of the eighteenth-century by the then new science of political economy. At the period, the term civil society was starting to be employed in a different way from the tradicional (where civil society is sinonimous to State), meaning a sphere organized around non-political principles demanding new conceptual tools.
\end{abstract}

\section{KEY WORDS}

Civil Society, Natural Rights Theory, Political Economy, Need, Justice, Police. 


\section{Sociedade civil e economia política}

Na França da década de 1750 o termo sociedade civil era sinônimo de estado e corpo político: qualquer comunidade humana organizada em torno de um soberano e tendo em vista o bem comum poderia ser assim denominada nos escritos de filósofos e economistas. É o que vemos, por exemplo, no verbete Estado [État] do sexto volume da Enciclopédia de Diderot e d'Alembert, publicado em I756, assinado por Jaucourt:

Pode-se definir o estado [état], uma sociedade civil (société civile), pela qual uma multidão de homens está unida sob a dependência de um soberano para desfrutar de sua proteção e de seus cuidados, da segurança e da bondade que faltam ao estado de natureza. [...] Essa união de várias pessoas em um único corpo, produzido pelo concurso das vontades e das forças de cada particular, distingue o estado de uma multidão. (Jaucourt, "État", in Diderot \& d'Alembert 1756, v. 6, p. 19).'

Em contraposição ao estado de natureza, na sociedade civil os indivíduos se encontram protegidos de inimigos externos e internos e têm suas posses garantidas pelo poder público por um soberano a quem devem obediência e suas atividades particulares adquirem um sentido mais amplo, como parte de um todo organizado, de um corpo político. É nesses termos que Derathé explica a hesitação de Rousseau em torno do título e subtítulo dos Manuscritos de Genebra para o Contrato Social. ${ }^{2}$ E, conforme explica Bobbio, esse uso do termo "corresponde ao significado tradicional de societas civilis, no qual civilis de civitas é sinônimo de politikós de pólis; e traduz exatamente a expressão koinonéia politikê" encontrada em Aristóteles (Bobbio 1986, p. 44).

Menos de 70 anos depois, em I820, Hegel propõe uma distinção entre sociedade civil [bürgerliche Gesellschaft] e Estado, pensados como momentos de uma teoria da eticidade ou vida ética [Sittlichkeit] e vendo nesta última uma esfera eminentemente moderna de socialização:

A sociedade civil é a diferença que intervém entre a família e o Estado, embora a sua formação plena ocorra mais tarde do que a do Estado, pois, como diferença, ela pressupóe o Estado, que ela, para existir, tem de ter diante de si como algo subsistente por si. A criação da sociedade

I Sempre que não houver indicação da tradução, ela é minha.

2 Derathé 2009, Apêndice, p. 550. 
civil pertence, de resto, ao mundo moderno, que, pela primeira vez, faz justiça a todas as determinações da Ideia. (FD, $\$$ I82, adendo) ${ }^{3}$

A sociedade civil tem na "pessoa concreta", em seu relacionamento multifacetado e diverso com outras pessoas, seu princípio (FD, \$ I82). É precisamente aí que a "prescrição do direito: [...] seja uma pessoa e respeite as outras enquanto pessoas" (Ibid., § 36) adquire a consistência de uma "esfera externa" (FD, § 4I). No relacionamento interpessoal, onde cada indivíduo particular se defronta com outro particular, uma primeira universalidade aparece (na dupla forma jurídico-econômica de pessoa em geral e de valor econômico, ambos interligados na figura do contrato), condicionando essa interação e fundando um "sistema de dependência omnilateral, tal que a subsistência e o bem-próprio do singular, bem como o seu ser-aí jurídico, estão entrelaçados com a subsistência, o bem próprio e o direito de todos" (FD, $\$$ I83). Com efeito, cabe à sociedade civil inscrever o direito no plano antropológico das carências, ou idealizar a natureza humana, inclusive em sua dimensão animal ${ }^{4}$ :

Não podíamos passar do direito em si para a administração do direito, porque não tínhamos ainda o solo no qual o direito podia existir, podia ser administrado. $\mathrm{O}$ fato de que o direito agora é sabido, de que ele vige como algo universalmente válido, pertence a esta existência. Pois precisamente, a carência do próprio direito tem de residir na particularidade, na existência enquanto tal, portanto, o próprio direito é a carência suprema. (FD, $\$ 2$ IO, anotação)

Encontra-se precisamente aí o que Hegel define como o "estado externo" $(\mathrm{FD}, \$ \mathrm{I} 83)$, cuja teorização primeira devemos aos teóricos modernos do direito natural (ou jusnaturalismo):

O Estado é representado como uma unidade de pessoas diversas, como uma unidade que é somente ser-em-comum, então só se visa com isso a determinação da sociedade civil. Muitos teóricos modernos do Estado não puderam alcançar nenhuma outra maneira de ver o Estado. (FD, $\$ I82, adendo)

3 Todas as citações da Filosofia do direito remetem à edição da Suhrkamp (Hegel 1986), seguida do parágrafo e com a indicação de anotação ou adendo. Sempre que disponível, como aqui, utilizo a tradução de Marcos L. Müller (Hegel 2000 e I998).

4 A sociedade civil se caracteriza por esse duplo processo de abstração: de um lado as carências são multiplicadas, de outro, os meios de sua satisfação, a saber, o trabalho é subdivido e se torna altamente especializado. 
O problema com as concepções ditas "empiristas" é duplo: nelas "a totalidade do orgânico não é alcançada" e, dentro desta, uma "determinidade" é separada do todo, e tomada "como a essência da relação" (Hegel 2007, p. 4I). Através da "ficção da imaginação como estado de natureza" buscou-se separar "da imagem misturada do estado de direito tudo o que é arbitrário e contingente", restando apenas o homem "em sua nudez, ou a abstração do homem com suas possibilidades essenciais"s (Ibid., p. 46 e 47). Entendido o homem desse modo, como elemento "simples e separado posto como originário", como átomo, "a unidade" construída a partir das interações entre os indivíduos "não pode, como na física empírica, representar nada, senão, novamente, as intricações multiformes [...] dos contatos superficiais destas qualidades", recebendo o "nome vazio de uma harmonia informe e exterior, sob o nome da sociedade ou do estado" (Ibid., pp. 48-49). Hegel insiste no que, a seus olhos, é uma confusão:

Se o estado é confundido com a sociedade civil-burguesa e se a sua determinação é posta na segurança e na proteção da propriedade e da liberdade pessoal, então é o interesse dos singulares enquanto tais o fim derradeiro em vista do qual eles estão unidos, e daí segue-se, igualmente, que depende do bel-prazer ser membro do Estado. (FD, $\$ 258$ )

Em sua Enciclopédia, Hegel implicitamente retoma a referência à física, apresentando a sociedade civil como "o sistema da atomística" (I995, $\$$ 523), sistema que tem uma ciência própria:

A Economia Política é a ciência que tem seu começo nestes pontos de vista, mas ela tem então de expor a relação e o movimento das massas na sua determinidade qualitativa e quantitativa e no seu emaranhamento. Esta é uma das ciências que surgiram na época moderna como seu terreno. O seu desenvolvimento mostra o aspecto interessante de como o pensamento (veja-se Smith, Say, Ricardo) descobre na multidão infinita de singularidades que estão inicialmente diante dele e extrai dela os princípios simples da coisa, e entendimento que nela opera e que a rege. (FD, $\$$ I89)

Para Hegel, a economia política revela aquilo que as teorias jusnaturalistas strictu sensu já vinham tematizando, embora talvez de forma ainda confusa, em

5 Na sociedade civil "o homem vale porque é homem, e não porque seja judeu, católico, protestante, alemão, italiano, etc.” (I986, \$209). 
particular por ver ali interações de tipo predominantemente político e denominar a comunidade resultante de Estado. A economia política, por sua vez, é

uma ciência que honra ao pensamento, porque ela encontra as leis para uma massa de contingências. É um espetáculo interessante observar como todas as conexōes atuam, aqui, retroativamente, como as esferas particulares se agrupam, têm influência sobre as outras e delas experimentam o seu fomento ou o seu impedimento. Este entrosamento, em que inicialmente não se acredita, porque tudo parece entregue ao arbítrio da singularidade, é especialmente notável e tem semelhança com o sistema planetário, que ao olho sempre mostra somente movimentos irregulares, mas cujas leis podem, contudo, ser conhecidas. ${ }^{6}$ (FD, $\$$ I89, adendo)

Espécie de física moral, a economia política já aparece em Hegel como uma ciência cujo objeto são as interações de base das sociedades modernas (o sistema de carências), sobre as quais se erguem o aparato institucional de administração do direito e da polícia [Polizei], os outros dois momentos da sociedade civil, e perante aos quais se constitui o "Estado propriamente político" (FD, \$267), isto é, o estado em sentido estrito, em sua constituição interna e aparato institucional dos poderes. Ao lado da família, a sociedade civil e o Estado político, constituem, por sua vez, o Estado em sentido lato, enquanto "totalidade ética absoluta" (Hegel 2007, p. 83). No que segue, buscarei demonstrar, de modo bastante sucinto, como esses três momentos da sociedade civil são alterados pelo surgimento da economia política.

\section{Direito natural e economia política}

Em I8I5, por ocasião da publicação dos Princípios de economia política, de Jean-Baptiste Say, o fisiocrata Dupont de Nemours censura a definição que o autor oferece do objeto próprio a essa ciência: "diminuístes demais o campo de trabalho [carrière $]^{7} \mathrm{da}$ economia política ao tratá-la como a ciência das riquezas. Ela é a ciência do direito natural aplicado, como ele deve o ser, às sociedades civilizadas" (I8I5, sem página).

A seus olhos, a definição, que se tornará canônica, de economia política como

6 Sobre as fontes escocesas da interpretação hegeliana da economia política ver Chamley (1963); Waszek (1988).

7 Um dos significados do termo carrière é o de campo de escavação de minérios, geralmente a céu aberto. É nesse sentido, de campo de trabalho ou de exploração que Nemours emprega o termo aqui. 
a ciência da produção e distribuição da riqueza ${ }^{8}$ é estreita demais. Como alguns estudos recentes vêm demonstrando, a concepção da economia política como "direito natural aplicado" ou, de modo mais geral, como um desdobramento interno à tradição jusnaturalista, era a defendida por seus principais teóricos no século XVIII.' A questão é particularmente interessante, dentre outros aspectos, pois é esse desdobramento que permitirá a definição mais estreita, no início do século XIX, quando a relação com a tradição jusnaturalista é menos evidente.

A primeira inovação que essa ciência traz ao jusnaturalismo é a associação da tese da sociabilidade natural à ideia de excedente. A ideia é relativamente simples: não há sociabilidade possível sem excedente físico de produção sobre o consumo, excedente que será o conteúdo do comércio. O cerne dessa ideia é sintetizado pela expressão necessidades (ou carências) recíprocas (reciprocal wants, em inglês, besoins reciproques, em francês): na formulação sintética de Anne-Robert Jacques Turgot "todo comércio está fundado sobre necessidade recíprocas" (OT1, p. 440) ${ }^{\mathrm{II}}$ E, para que o comércio funcione corretamente, basta garantir a "liberdade geral de comprar e vender", o que necessariamente pressupõe concorrência entre vendedores e compradores: "A concorrência é um dos mais importantes princípios do comércio e uma parte considerável de sua liberdade", ela é "a alma da liberdade bem compreendida" (Forbonnais, verbete "Comércio", in Diderot \& d'Alembert 20I5, p. 80 e 84). O princípio da concorrência é a base da ciência do comércio (science of trade, em inglês, science du commerce, em francês). Em uma carta a Dupont de Nemours, datada de 1766, onde Turgot busca aproximar Vincent Gournay de François Quesnay (o fundador da fisiocracia e, com ela, da economia política propriamente dita) ${ }^{\mathrm{I} 2}$, encontramos um indício precioso a respeito de como a economia política se diferencia dessa ciência do comércio:

Às vezes acho que você não leva seus princípios às últimas consequências e que, mantendo-se na senda aberta pelo nosso doutor [Quesnay], você

8 Definição que se inicia com Turgot, com suas Reflexôes sobre a formação e distribuição de riquezas, de I766, passa por Say, cujos Princípios de economia política foi publicado e censurado em I802, sendo reeditado em I8I5, até chegar a Ricardo, cujos Princípios de economia política e tributação é de I8I7.

9 Sobre a fisiocracia, ver Larrère, I992; sobre a teoria do comércio internacional em Hume e Smith, ver Hont, 2005.

Io A expressão reciprocal wants se encontra na obra de Sir James Steaurt (IPPO, p. 40).

II A edição mais completa das obras de Turgot ainda é a de Gustave Schelle, em cinco volumes publicados entre I9I3 e I923. Tomei a liberdade de citá-las pelo volume, sem a data, seguida da página.

I2 Marx e Schumpeter partilham dessa visão (Quesnay 1984, p. 7; cf. Larrère I992, pp. 5-6). 
fica excessivamente preso à análise profunda, que foi ele o primeiro a realizar, da formação, circulação e reprodução dos rendimentos. Isto não lhe permite fazer uso adequado do princípio menos abstrato, mas talvez mais esclarecedor, mais fecundo, ou pelo menos mais peremptório por sua simplicidade e por seu caráter inequivocadamente universal, que é o princípio da concorrência e da liberdade do comércio, consequência imediata do direito da propriedade e da faculdade que tem cada indivíduo de conhecer seus interesses melhor do que ninguém. A Gournay bastou esse princípio para que ele chegasse, partindo do balcão, aos mesmíssimos resultados práticos a que chegara, partindo da charrua, o nosso doutor. (Turgot, in Figueira 2000, p. 219)

Se as consequências práticas (liberalizantes) de ambos os sistemas, comercial e agrícola, são muito parecidas, a diferença teórica, por sua vez, concerne à "análise profunda" da "formação, circulação e reprodução dos rendimentos". O primeiro texto econômico do fundador da fisiocracia, os verbetes Arrendatários (Fermiers) e Cereais (Grains) da Enciclopédia (I756), partem da comparação entre as duas técnicas disponíveis à agricultura francesa de meados do século xviII: o cultivo tradicional, por meeiros, de pequenas propriedades com bois e o cultivo com cavalos, mais demandante de recursos no início, posto em prática apenas por ricos arrendatários em grandes propriedades. Da observação minuciosa e precisa das diferenças entre esses métodos nasce não apenas a constatação da superioridade, em termos de produtividade, da grande cultura, como a apreensão teórica da origem de um excedente não apenas físico, mas também monetário, o produto líquido [produit net] — o que pressupõe a observação do bon prix, isto é, um preço capaz de repor os custos de produção envolvidos. O famoso Quadro econômico [Tableau économique], por sua vez, descreve o circuito desse rendimento excedente e, com ele, da totalidade das riquezas de um país:

Vemos assim, com um simples olhar, o emprego e o volume das riquezas e dos homens, as suas relações e influências recíprocas e toda a essência do governo econômico dos estados agrícolas. Assim, o zigue-zague, bem compreendido, abrevia muito os pormenores e apresenta a nossos olhos as ideias tão emaranhadas que a inteligência, por si, teria muita dificuldade em apreender, esclarecer e relacionar pela simples via discursiva. (Quesnay 1984, pp. II5-II7)

A "essência do governo econômico dos estados agrícolas" — cuja análise se constrói pela generalização do paradigma da fazenda administrada por um rico 
arrendatário, capaz de empregar os métodos mais caros, porém mais produtivos, de produção disponíveis - pode então ser facilmente visualizada "com um simples olhar". ${ }^{13}$ Aí a inovação trazida da fisiocracia: para a reprodução do corpo político não basta apenas a existência de um excedente físico, é preciso que exista também um excedente monetário, isto é, que exista capital disponível. Conceito que faz sua estreia em 1766, nas Reflexões sobre a formação e a distribuição das riquezas, de Turgot:

Do que foi dito, vê-se como a cultura das terras, as fábricas de todos os gêneros e todos os ramos do comércio rodam [roulent] sobre uma massa de capitais ou de riquezas mobiliárias acumuladas que, antes de serem investidas [avancées] pelos empreendedores em cada um desses diferentes tipos de trabalho, devem ter-lhe retornado a cada ano com um lucro constante; isto é, [é preciso] o capital para que possa ser revertido e investido [reversé et avancé] novamente na continuação dos mesmos empreendimentos [entreprises], e o lucro para a subsistência mais ou menos agradável dos empreendedores. (От2, p. 575)

A noção de capital traz consigo outra, igualmente indispensável para a econômica política, o valor:

Qualquer um, seja pela renda de sua terra, seja pelos salários de seu trabalho ou de sua indústria, recebendo cada ano mais valor [plus de valoir] do que ele tem necessidade [besoin] de gastar, pode colocar esse excendente [superflu] numa reserva e acumulá-lo: esses valores acumulados são o que se denominou um capital. ${ }^{\mathrm{I} 4}$ (от2, p. 567)

Retomando os conceitos com que abrimos esse artigo, podemos finalmente compreender a lição sintética de Turgot ao controlador geral em suas Cartas sobre o comércio de cereais, de 1770 :

O fazendeiro [cultivateur] consome imediatamente o que é necessário a sua alimentação; o resto se divide entre ele e o proprietário, e todos os dois, através de seus gastos [...] distribuem esse resto para todos os

I3 Sobre Quesnay, em geral, ver Kuntz (1982), Markovitz (1986), Larrère (1992), Monzani (2014). Sobre as questões econômicas em particular, ver Santos (1996 e 1997).

I4 A teoria do valor de Turgot foi desenvolvida em linhas gerais no manuscrito Valores e moedas, geralmente datado de 1769 . Tratava-se, muito provavelmente, de um verbete para o Novo dicionário de comércio de André Morellet e do qual apenas o Prospecto foi efetivamente publicado (I769). Para um comentário ver Van den Berg (20I4). 
outros membros da sociedade como pagamento [salaire] pelo preço de seu trabalho. Os valores que esses recebem retornam, através da compra de bens agrícolas [denrées] que eles consomem, às mãos dos fazendeiros para daí de novo sair através de uma circulação cuja continuidade dá a vida do corpo político [une circulation dont la continuité fait la vie du corps politique] assim como a circulação do sangue dá vida ao corpo animal. (от3, p. 286)

O que anima o corpo político aqui não é a soberania (como em Hobbes e Hegel $)^{15}$, mas sim a circulação do valor. ${ }^{16}$ Mesmo ainda partilhando do "erro capital" do sistema fisiocrata, de considerar todo trabalho que não esteja diretamente envolvido na agricultura como estéril em termos de valor (WN Iv.ix.29, p. 674), nessa passagem, Turgot apresenta uma concepção de corpo político bastante diferente daquela de Jaucourt no verbete "Estado" da Enciclopédia, uma que deriva mais da economia que da política:

A necessidade [nécessité] do empréstimo a juros [prêt à intérêt] para o comércio e, consequentemente, para a sociedade civil [société civile], é provada antes de tudo [d'abord] pela tolerância que a carência absoluta do comércio forçou a ser aceita nesse tipo de negociação, apesar dos preconceitos rigorosos tanto de teólogos quanto de jurisconsultos. (Отз, p. I68)

Aqui, a "necessidade absoluta do crédito para a prosperidade e para a manutenção do comércio" é demonstrada a partir dos "verdadeiros princípios do direito natural sobre a matéria dos juros do dinheiro" (от3, p. 167). Desse modo, as exigências puramente comerciais (como o crédito) não apenas atropelam preconceitos religiosos ou políticos, como se tornam as exigências da própria sociedade civil. E se Turgot ainda oscila no uso dos termos sociedade civil, corpo político e Estado, as ideias que as sustentam se tornam cada vez mais claras (ver seção 4 , abaixo).

\section{Administração da justiça em uma sociedade comercial}

Ao apresentar a ideia da sociabilidade natural do homem, Pufendorf apontava que

I5 Na introdução ao Leviatã, Hobbes apresenta a "Common-wealth, or State, (in latine Civitas)" como um "Artificiall Man”, cuja "Artificiall Soul” é a "Soveraignty" (I985, p. 8I).

I6 Turgot talvez seja o primeiro a empregar essa metáfora que, nas mãos de Marx, ganha novos contornos (1983, pp. I88189). 
ela deriva de um sentimento desinteressado, de uma "benevolência universal", uma "amizade geral":

Pois a natureza certamente estabeleceu entre todos os homens uma amizade geral, da qual ninguém deve ser excluído, a menos que tenha se tornado indigno por algum grande crime. E ainda que, por um efeito admirável da sabedoria do criador, as leis humanas encontrem-se de tal modo proporcionais à natureza humana que sua observação seja sempre vantajosa e, por consequência, que retorne a todos um enorme bem dessa amizade geral; entretanto, quando se trata de estabelecer seu fundamento, não se deve buscá-lo na utilidade que dela se retira, mas na conformidade de uma mesma natureza. (Pufendorf, Livro II, cap. 3 , $\$$ I8, I706, p. 184)

Apesar de fundada sobre uma espécie de sentimento desinteressado presente em cada um dos homens, a ordem por ele gerada é útil a todos, igualmente satisfazendo os múltiplos interesses privados aí envolvidos:

De modo algum o amor próprio exclui [répugne] a sociabilidade de nossa alma, desde que ele não perturbe a ordem e a harmonia da sociedade. Pois a natureza, ao nos ordenar que sejamos sociáveis, não pretende que nos esqueçamos de nós mesmos. A finalidade da sociabilidade é que, ao contrário, por um comércio de auxílios e serviços, cada um possa prover melhor seus próprios interesses. (Ibid.)

Em sua Teoria dos sentimentos morais, de I759, Adam Smith articula essa mesma tríade a partir de sua teoria da simpatia, a qual organiza as paixões numa tipologia com três espécies: as sociáveis, as insociáveis e as egoístas. As paixões sociáveis são em tudo agradáveis, e o grau em que simpatizamos com ela bastante elevado; já as paixões insociáveis são desagradáveis em si mesmas e em seus efeitos, exigindo um grau bastante baixo de intensidade para permitir a simpatia; as paixóes egoístas, por sua vez, "nunca é tão gracioso quanto às vezes é o primeiro grupo, nem tão odioso quanto às vezes é o segundo", ocupam um lugar intermediário entre elas, exigindo o mesmo para que possamos com elas simpatizar (TSM, p. 46). Três diferentes paixões que fundam três diferentes tipos de interações e de laços sociais. Comecemos pelas paixões sociáveis, cujo paradigma são as relações familiares e de amizade:

Todos os membros da sociedade humana precisam da ajuda uns dos outros, e estão igualmente expostos a ofensas mútuas. Onde a ajuda 
necessária é reciprocamente provida pelo amor, gratidão, amizade e estima, a sociedade floresce e é feliz. Todos os seus diferentes membros estão atados entre si pelos agradáveis elos do amor e afeição, como se atraídos para um centro comum de bons serviços recíprocos [mutual good offices]. (TSM, p. I06)

O segundo tipo de interação é aquele próprio às paixões egoístas, que aqui é associada às relações mercantis:

A sociedade pode subsistir entre diferentes homens, como entre diferentes mercadores [merchants], por um senso de sua utilidade [sense of its utility], sem qualquer amor ou afeto recíprocos; e embora nenhum homem que vive em sociedade deva obediência ou esteja atado a outro por gratidão, ainda assim é possível mantê-la por uma troca mercenária de bons serviços [mercenary exchange of good offices], segundo uma valoração acordada [agreed valuation] entre eles. (TSM, p. I07)

Evidentemente, trata-se de laços menos agradáveis, mas ainda assim capazes de regular interaçôes sociais e organizar, através do valor, as trocas necessárias à existência dos indivíduos. Como podemos entrever, são as interações que serão tomadas como o objeto principal da então nascente economia política, resultado do que Istvan Hont denominou de "sociabilidade comercial (commercial sociability)" e que, como visto na seção anterior, outros autores teorizam a partir da noção de "carências recíprocas". Por fim, as paixões insociáveis, opostas às paixões sociáveis, geram um tipo de interação que precisa, ao máximo, ser evitado:

A sociedade, entretanto, não pode subsistir entre os que estão sempre prontos a se ferir mutuamente. No momento em que tem início a ofensa [injury], no momento em que se instalam ressentimento e animosidade mútuos, rompem-se todos os elos da sociedade, e os diferentes membros de que ela consistia ficam como que dissipados e espalhados pela violência e oposição de seus afetos discordantes. [...] A beneficência é, assim, menos essencial à existência da sociedade que a justiça. A sociedade poderá subsistir, ainda que não segundo a condição mais confortável, mas a prevalência da injustiça deverá destruí-la completamente. (TSM, p. IO7)

I7 Ver os dois primeiros capítulos de Hont (2015); e Force (2003); Rassmussen (2008). 
Explica-se assim o nome que Smith dá a esse tipo de paixão: insociável porque as interaçóes geradas por elas esgarçam o tecido social, levando, no limite, à morte do corpo político. A relação conflituosa aí gerada deve, então, ser regulada de modo peculiar, através do emprego da força (TSM, pp. 98-99). O sistema moral de Smith ganha assim um segundo degrau: cada tipo de paixão engendra uma espécie de interação social caracterizada por um laço social específico. Já se entrevê um terceiro nível para esse sistema: as relaçôes conflituosas geradas pelas paixões insociáveis precisam ser reguladas pela virtude da justiça; as relações agradáveis criadas pelas paixões sociáveis são o objeto da benevolência (TSM, p. 273) e, por fim, a administração das relações econômicas engendradas pelas paixões egoístas fica a cargo da prudência (TSM, p. 265).

O sistema é completado pela delimitação de cada uma dessas séries: à "jurisprudência natural" cabe a análise da justiça, isso é, da administração dos conflitos próprios às interações fundadas nas paixões insociáveis, o que se dará através de leis positivas (TSM, p. 273); a economia política, lida, por sua vez, com as interações geradas pelas paixões egoístas, relaçóes sociais que se concretizam na riqueza e que tem no valor seu eixo central; por fim, as paixões sociáveis criam relações e laços agradáveis, objeto da benevolência e que não possuem uma ciência específica, ou ao menos não uma nomeada por ele. No último parágrafo da Teoria, Smith aponta que a junção dessas duas ciências (jurisprudência natural e economia política) perfaz a jurisprudência, verdadeira "ciência do homem de estado ou legislador [stateman or legislator]" (wN, p. 428), cujo objeto são "os princípios gerais da lei e do governo [...] não apenas no que diz respeito à justiça, mas à polícia [police], finanças públicas [revenue], exército e tudo o mais que seja objeto da lei" (TSM, p. 428). É nesse contexto que os termos civil society e commonwealth são empregados como sinônimos, quase como lado passivo e ativo da comunidade:

Todo sistema de lei positiva pode ser considerado uma tentativa mais ou menos imperfeita de se atingir um sistema de jurisprudência natural, ou uma enumeração das regras particulares de justiça. Como jamais aceitarão uns dos outros a violação da justiça, o magistrado público necessita empregar o poder da república [commonwealth] para fazer cumprir a prática dessa virtude. Sem essa precaução, a sociedade civil [civil society] se tornaria um cenário de carnificina e desordem, pois cada homem se vingaria com suas próprias mãos sempre que se imaginasse ofendido. ${ }^{18}$ (TSM, p. 426)

I8 Sobre a teoria da justiça de Smith, ver Haakonssen (I98I); e também Fleischacker (2004). 
Aos olhos de Hegel temos aqui um excelente exemplo da redução do estado à sociedade civil: ele é visto aqui unicamente como o mantenedor da ordem interpessoal, isto é, como mero garantidor dos direitos próprios à pessoa (vida, honra e propriedade); sem que as questôes próprias à soberania (interna e externa) possam ser corretamente tematizadas. Em oposição à sociedade civil, esfera de realização e expansão da personalidade dos indivíduos, o estado adquire sua "personalidade" através do conceito de soberania: "O idealismo que constitui a soberania é a mesma determinação em virtude da qual no organismo animal as assim chamadas partes do mesmo não são partes, mas membros, momentos orgânicos, cujo isolamento e subsistir por si é a doença [...]". (FD, \$278, anotação)

Para Hegel, a soberania é a alma do corpo político, capaz de transformar o todo composto pelos indivíduos, estamentos e corporaçôes da sociedade civil, de mero "agregado [Aggregat]" em "organismo"19 (Ibid.), corpo propriamente dito, onde a vida "está em cada ponto, só há uma vida em todos os pontos, e não há resistência alguma contra ela” (FD, $\$ 276$, adendo). Como Rousseau, que no Contrato social distingue entre comunidades constituídas por mera "agregação" dos verdadeiros "corpo políticos", construídos por "associação" em torno de um "bem comum" (oc3, p. 360), Hegel também não vê em ação na dinâmica interpessoal própria à sociedade civil um princípio de unidade capaz de dar vida ao corpo político. Os economistas políticos continuam falando em corpo político, mas o tipo de integração que eles veem em operação na sociedade civil exige um outro conceito, o de arranjo.

\section{Polícia entre Estado e civilização}

O terceiro momento da sociedade civil em Hegel é o da polícia. Tema que, ao longo do século XVIII abrange dois tópicos geralmente tematizados em separado: a civilização e o governo. O primeiro deles aparece no uso do termo como adjetivo:

Civilisé era, como cultivé, poli, policé, um dos muitos termos, não raro usados quase como sinônimos, com os quais os membros da corte gostavam de se designar, em sentido amplo ou restrito, a qualidade específica de seu próprio comportamento, e com os quais comparavam o refinamento de suas maneiras sociais, seu "padrão", com as maneiras de indivíduos mais simples e socialmente inferiores. (Elias 20II, p. 52)

I9 Hegel refere-se à "monarquia feudal de outrora" como um todo que é "mais um agregado do que um organismo" (FD $\$ 278$, anotação), o que também indica que a soberania é característica do Estado moderno. 
Eis um dos temas centrais nos escritos do jovem Turgot: "Em todos povos civilizados, as cidades, por sua natureza, são o centro do comércio e das forças da sociedade" (от1, p. 230). Povos civilizados traduz "peuples policés", mas também lemos "passions policés" (от1, p. 136), "langues policés" (OT1, p. I64), "nations policés" (от1, p. 205), em suma, "homme policé" em contraposição ao "homme sauvage" (OT1, p. 243). Encontramos aqui, por um lado, toda uma temática da disciplina do $\operatorname{corpo}^{20}$, por outro, um movimento consciente de reforma governamental que encontrou na economia política sua vanguarda:

A fisiocracia [...] não se limita em absoluto à economia, sendo na verdade um sistema em grande escala de reforma social e política. Contém, de forma incisiva, abstrata, dogmática, endurecida, ideias que [...] caracterizam todo o movimento do qual Turgot, na ocasião encarregado das finanças, foi um dos expoentes. Se esta tendência (que nem tinha nome nem organização unificada) tivesse que recebê-lo, poderia ser chamada de burocracia reformista. Mas esses administradores tinham também indubitavelmente por trás de si segmentos da intelligentsia e da burguesia comercial. (Elias 20II, p. 54)

Movimento não homogêneo (Elias insiste no debate entre a ciência do comércio na figura de Forbonnais, e a fisiocracia), mas indiscutivelmente reformista, tendo na burguesia comercial sua base de sustentação. $O$ ponto que nos interessa é o papel desempenhado pela descoberta da sociabilidade própria às interações interpessoais e que tem no comércio o seu campo privilegiado. Ao revelar a trama não necessariamente política que une os homens em comunidades, a economia política traz consigo uma série de novas questôes à filosofia política. A disciplina que se verá mais afetada é a polícia:

Polícia [police] é a segunda divisão geral da jurisrpudência. O nome é francês e deriva originalmente do grego politeia, que significava propriamente a administração [policey] do governo civil, mas que hoje significa apenas a regulação das partes inferiores do governo, a saber, limpeza, segurança e o preço dos bens [cheapness or plenty]. (LJ, p. 486)

Mesmo Adam Smith, em suas Preleçôes de Jurisprudência (notas de aulas referentes aos anos de I762-63 e I766), tomava as "considerações sobre o preço dos bens [cheapness or plenty], ou, o que é a mesma coisa, o modo mais adequado

20 Estudada por Elias (20II), e por Foucault (2008 e 2004). 
de fornecer riqueza e abundância" (LJ, p. 487), como um campo de aplicação da jurisprudência. Uma das passagens que melhor apresenta o alcance das alterações provocadas nesse campo pelo estabelecimento da economia política como uma ciência específica saiu da pena de um autor lido a fundo por Hegel, Sir James Steuart:

O poder de um príncipe moderno, suponha-se, pela constituição de seu reino, tão absoluto quanto possível, imediatamente se torna limitado tão logo ele estabelece o plano de economia que estamos tentando explicar. Se anteriormente sua autoridade se assemelhava à solidez e força da cunha (que pode, indiferentemente, ser utilizada para dividir troncos, pedras e outros corpos duros, e que pode ser deixada de lado e retomada a bel prazer), lentamente ela se assemelhará à delicadeza de um relógio, que é bom unicamente para marcar a progressão do tempo, e que é imediatamente destruído ao ser utilizado de outro modo ou tocado de forma indelicada [or touched with any but the gentlest hand]. (IPpo, pp. 278-279)

Se o monarca absolutista dispunha de sua autoridade como de uma cunha, utilizando-a sempre do mesmo modo e para todos os fins, lançando mão dela a seu bel-prazer, a partir da instauração de um plano de economia política a natureza mesma de seu poder se vê alterada: ele se torna mais dependente da organização do corpo social, empregando mecanismos mais complexos e refinados, voltados a finalidades mais específicas e precisas. $\mathrm{O}$ manejo do poder nas sociedades modernas exige conhecimentos técnicos e habilidade por parte do governante, a menor falta destes causando a destruição completa do delicado e complexo mecanismo. Do ponto de vista do estado, a economia política aparece como o mais importante freio (bridle, literalmente, cabresto, utilizado não apenas para frear, mas também para conduzir o cavalo) ao uso ilimitado do poder:

Do mesmo modo que a economia moderna é, pois, o mais efetivo freio [bridle] já inventado contra a insensatez [folly] do despotismo; também a sabedoria de um grande poder nunca reluz com mais brilho quando observada exercendo-se em planejar e executar essa economia, como um freio contra o seu próprio exercício irresponsável [wanton] em gerações futuras. (Ibid.)

A economia de um reino moderno, isto é, sua constituição e organização interna, adquire tamanho grau de complexidade que ao soberano resta, ou alterar 
o tipo de interferência - a polícia como arte de administrar a vida e o bem-estar da população - , ou então pautar sua ação precisamente na não-intervenção nas operaçóes desse arranjo criado pela livre iniciativa dos indivíduos. Em seu Account of the Life and Writings of Adam Smith (1793), Dugald Stewart formula a questão de forma sintética:

Esses [obstáculos] que surgiram a partir das desordens dos tempos feudais, ao obstruir a livre circulação do trabalho e do capital de emprego a emprego e de lugar a lugar, tendiam diretamente a perturbar [disturb] os arranjos internos da sociedade [internal arrangements of society]. (in EPS, p. 316)

É precisamente esse "arranjo interno da sociedade" que a economia política revela. Nem agregação, nem associação, arranjo parece ser a melhor tradução para os termos empregados por Smith (arrangement) e por Turgot (assemblage) ao discutir o tipo de "maquinaria ou organização [machinery or oeconomy]" (TMS IV.1.9, p. I83) aí envolvido:

A palavra nação não foi até agora bem definida, porque frequentemente se confunde as nações com os corpos políticos ou os Estados. Uma nação é uma reunião [assemblage] de homens que falam a mesma língua materna. [...] Um Estado é uma reunião de homens sob um mesmo governo. $^{21}$ (от2, p. 637)

Nesse texto, que data de 1767 , reencontramos a sinonímia entre sociedade civil e estado, através da noção de corpo político, mas ela só pode ser assumida ao custo de considerar como exceçôes os pequenos estados que se formam em torno de cidades comerciais:

O território e o comércio dessas cidades de entreposto são dois correlativos necessários um ao outro, e a distinção entre comércio de produtos do solo e comércio de entreposto ou de revenda é nula quando se fala de nações ou de regiōes. Não há dúvida que certas cidades e costas marítimas, que servem de entreposto a um comércio extenso, tenham podido, pelo acaso das circunstâncias [par le hasard des circonstances], formar pequenos Estados políticos separados do território de que elas são o entreposto; mas esse acaso não altera a natureza a natureza das coisas. (от2, p. 639)

2I Sobre o conceito de assemblage, ver também as cartas a Condorcet onde ele é empregado a propósito da constituição de grandes cristais a partir de cristais menores (ОT3, pp. 579-590). 
A questão é precisamente essa: se, pelo acaso das circunstâncias, a Holanda é o entreposto de regiōes submetidas a outros estados, a reunião natural que as "carências recíprocas" dessas regiōes estabelece não é ordem política, estando mais próxima do tipo de relação criada entre povos que partilham da mesma língua materna. Nem nação, nem estado, a economia política (por vezes inclusive à revelia dos economistas) desvela a tessitura econômica própria à sociedade civil e, com ela, a da civilização ocidental.

\section{Conclusão: 0 arranjo interno da sociedade}

Se a interpretação aqui proposta estiver correta, a economia política surge com a introdução da noção de excedente na tese da sociabilidade natural do homem (o que já ocorria na ciência do comércio), e da formulação, pelos fisiocratas, de um esquema teórico de apreensão da "formação, circulação e reprodução" desse excedente. Precisamente o esquema é descrito pelo famoso Quadro econômico de Quesnay. Essa nova apreensão do mecanismo de base do corpo político traz consigo uma série de questôes e problemas que exigirão um enorme esforço intelectual por parte das geraçôes subsequente de economistas políticos. ${ }^{22} \mathrm{Um}$ passo decisivo nesse sentido foi a associação entre valor e capital operada por Turgot em suas Reflexôes, permitindo a teorização do núcleo dinamizador desse circuito que tem na sociedade civil o seu espaço de atuação.

Sociedade civil cuja estrutura, cujo "arranjo interno" será igualmente objeto dessa nova ciência: o Livro I da Riqueza das naçōes, por exemplo, intitula-se, "Das causas do aprimoramento dos poderes produtivos do trabalho e da ordem segundo a qual o seu produto é naturalmente distribuído entre as diferentes classes do povo [ranks of the people]". Essa ordem 'natural' é determinada pelo tipo de recurso produtivo (pelo fator de produção, diriam os economistas atuais) com que cada indivíduo participa da produção da riqueza social (trabalho, capital ou terra) e com o tipo de rendimento recebe (salário, lucro ou renda). ${ }^{23}$ Dessa distinção funcional decorre uma separação de interesses que se encontram em tensão e mesmo oposição: a sociedade civil será perpassada por conflitos sistêmicos que se desdobram no tempo de acordo com os três estágios ou estados em que elas

22 "A aceitação desse conceito [excedente] implica em três problemas: o de sua avaliação, o de sua origem e o de sua atribuição" (Dobb I977, p. 26), cada um deles desdobrando-se no campo particular das teorias do valor, produção e distribuição, respectivamente.

23 Sobre a evolução interna ao pensamento de Adam Smith a esse respeito, entre a primeira edição (I759) da Teoria e a Riqueza (I776), devido à influência fisiocrática, ver Rodrigues (2017). 
podem se encontrar, progressivo, estacionário ou decadente. ${ }^{24}$ Por fim, essa esfera circunscreverá o campo de ação direta e imediata a um tipo específico de poder, de natureza não política:

Riqueza é poder, como diz Hobbes. Mas a pessoa que adquire ou herda uma grande fortuna não necessariamente adquire ou herda, com isso, qualquer poder político, seja civil ou militar. Talvez sua fortuna possa proporcionar-lhe os meios para adquirir esses dois poderes, mas a simples posse da fortuna não lhe assegurará nenhum deles. $\mathrm{O}$ poder que a posse dessa fortuna lhe assegura, de forma imediata e direta, é o poder de compra; um certo comando sobre todo o trabalho ou sobre todo o produto do trabalho que está então no mercado. (WN I.v.3; RN, p. 88)

A economia política do século XVIII descreve a sociedade civil como uma esfera organizada em classes com interesses conflitantes e dinamizada pela acumulação de capital. Uma esfera separada e relativamente autônoma ao Estado, na qual se exerce um tipo peculiar de poder e que tem no "interesse dos singulares enquanto tais o fim derradeiro em vista do qual eles estão unidos" ( $\mathrm{FD} \ 258$, anotação). Ao contrário, "O estado tem uma relação inteiramente diferente ao indivíduo", na qual "A união como tal, ela própria, é o verdadeiro conteúdo e fim, e a destinação dos indivíduos é levar uma vida universal” (FD $\$ 258$ ). Precisamente aí, na união dos indivíduos num corpo político organizado, Hegel buscará o solo adequado de compreensão do Estado político, em contraposição à sociedade civil como esfera de efetivação dos interesses particulares. A passagem da sociedade civil ao Estado marca o momento em que a economia política cede espaço à moderna teoria da soberania, em especial Hobbes e Rousseau. Como ensina Marcos L. Müller (2004), é a rearticulação especulativa em torno da tese do "idealismo da soberania" (FD $\$ 278$, anotação), em particular a reconfiguração do conceito de "soberania interna" como personalidade do Estado, que permitirá a Hegel teorizar a relação de oposição e complementaridade a partir da primazia do político sobre o econômico-jurídico (no sentido do direito privado) e, consequentemente, do Estado sobre a sociedade civil.

A breve reconstituição das origens teóricas da economia política aqui empreendida serve de prova da inegável proficuidade da teoria hegeliana da sociedade civil. Mas ela igualmente aponta para algumas vias abertas pelos economistas e não exploradas pelo idealismo absoluto, em torno, por exemplo, do conceito de arranjo (assemblage em Turgot, arrangement em Dugald Stewart). Aqui, o que

24 Ver WN I.xi. concl. 8-IO; RN, I996, pp. 272-273. 
está em jogo são diferentes concepções de todo, talvez incomensuráveis entre si: a partir do modelo iatro-mecanicista dos fisiocratas ${ }^{25}$, Turgot e Smith desenvolvem um modelo de geração orgânica por agregação que resulta, precisamente, em um arranjo social. Para o pensamento liberal do século xvıII, a economia, no sentido moderno termo (de interaçôes entre indivíduos autointeressados), constitui e fundamenta a economia, no sentido clássico do termo (de ordem interna), da sociedade civil.

\section{Referências bibliográficas}

Bоввіо, N. Estado, governo, sociedade. Para uma teoria geral da política. Rio de Janeiro: Paz e Terra, 1986.

Chamley, P. Economie politique et philosophie chez Steaurt et Hegel. Paris: Dalloz, 1963.

Derathe, R. Rousseau e a ciência política de seu tempo. São Paulo: Discurso Editorial e Barcarolla, 2009.

Diderot, D. \& D’Alembert, J. Encyclopédie, ou dictionnaire raisonné des sciences, des arts et des métiers. Ed. Robert Morrissey. University of Chicago: ARTFL Encyclopédie Project.

Diderot, D. \& D’Alembert, J. Enciclopédia, ou Dicionário razoado das ciências, das artes e dos oficios - Vol. 4: Política. Org. Pedro Paulo Pimenta e Maria das Graças de Souza. São Paulo: Editora Unesp, 2015.

Dовв, M. Teorias do valor e da distribuição desde Adam Smith. São Paulo: Martins Fontes, 1977.

Elias, N. O processo civilizador - Vol. 1: Uma história dos costumes. Rio de Janeiro: Jorge Zahar Editor, 200I.

Figueira, P. (Org.). Economistas Politicos. São Paulo: Musa Editora, 200I.

Fleischacker, S. On Adam Smith's "Wealth of Nations": A Philosophical Companion. Princeton: University Press, 2004.

Forbonnais, F. Elemens du commerce. Premiere et Seconde Partie. Seconde Edition. Paris, 1754 .

Force, P. Self-Interest Before Adam Smith. A Genealogy of Economic Science. Cambridge: University Press, 2003.

25 Ver Kuntz (1982, pp. I30I35) e Markovitz (I986, pp. I7I-I82). 
Foucault, M. La naissance de la biopolitique. Cours au Collège de France (1978-1979). Paris: Gallimard, 2004.

Segurança, território, população. Curso dado no Collège de France (1977-1978). São Paulo: Martins Fontes, 2008.

Haakonssen, K. The Science of a Legislator. Cambridge: C.U.P, I98I.

Hegel, G. W. F. Grundlinien der Philosophie des Rechts oder Naturrecht und Staatswissenschaft im Grundrisse (FD). Frankfurt: Suhrkamp, 1986.

Linhas fundamentais da filosofia do direito ou direito natural e ciência do estado em compêndio - Terceira parte: "A eticidade" - Segunda seção: "A Sociedade Civil” (FD). Trad. Marcos L. Müller. In: Textos Didáticos, no 21. Campinas: IFCH-Unicamp, 2000.

Linhas fundamentais da filosofia do direito ou direito natural e ciência do estado em compêndio - Terceira parte: "A eticidade" - Terceira seção: "O estado” (FD). Trad. Marcos L. Müller. In: Textos Didáticos, no 32. Campinas: IFCH-Unicamp, 1998.

Sobre as maneiras cientificas de tratar o direito natural. Trad. Agemir Bavaresco e Sérgio Christino. São Paulo: Loyola, 2007.

Enciclopédia das ciências em compêndio (1830). Volume III - A filosofia do espirito. Trad. Paulo Meneses Pe. José Machado. São Paulo: Edições Loyola, 1995.

Новвеs, T. Leviathan. Londres: Penguin, 1985.

Hont, I. Politics in Commercial Society. Cambridge: Harvard University Press, 2015. Jealousy of Trade. International Competition and the Nation-State in Historical Perspective. Cambridge: The Belknap Press of Harvard University, 2005.

Kuntz, R. Capitalismo e natureza. Ensaio sobre os fundadores da economia politica. São Paulo: Brasiliense, 1982.

Larrere, C. L'invention de l'économie au XVIII siècle. Paris: PUf, I992.

Markovits, F. L'ordre des échanges. Philosophie de l'économie et économie du discours au XVIII siècle en France. Paris: PUF, 1986.

Marx, K. O Capital, Vol I - tomo 1. Trad. R. Barbosa e F. R. Kothe. São Paulo: Abril Cultural, 1983 .

MonZani, L. R. "Raízes filosóficas da noção de ordem nos fisiocratas." In: Discurso n. 44 (2014), pp. 9-54.

Morellet, A. Prospectus d'um nouveau Dictionnaire de commerce. Paris: chez les Freres Estienne, 1769 . 
MülLER, M. L. "Estado e soberania: o 'idealismo da soberania". In: Lógica e ontologia - Ensaios em homenagem a Balthazar Barbosa Filho. Évora, F. Et. Al. (Orgs.). São Paulo: Discurso Editorial, 2004, pp. 263-290.

Nemours, D. “Lettre à J.-B. Say, 22/04/1815.” In: SAY, J.-B. Mélanges etcorrespondance d'économie politique/Correspondance avec Dupont de Nemours. Charles Comte (Org.). Paris: Chamerot, I833.

Pufendorf, S. Le droit de la nature et des gens ou Système général des principes les plus importans de la morale, de la jurisprudence, et de la politique. Trad., J. Barbeyrac. Amsterdã: Henri Schelte, 1706.

Quesnay, F. Quesnay. Economia. Trad. Rolf Kuntz. São Paulo: Ática, 1984.

Rassmussen, D. C. The Problems and Promise of Comercial Society: Adam Smith's Response to Rousseau. University Park: Pennsylvania State University Press, 2008.

Rodrigues, A. A. As concepçôes econômicas de Adam Smith: entre a ambição e a parcimônia. São Paulo (254 p.). Tese de doutorado em filosofia. FFLCH-usp, 2017.

Rousseau, J.-J. CEuvres complètes T. III. Du Contrat Social. Écrits politiques (OC3). Gagnebin, B.; Raymond, M (eds.). Paris: Editions Gallimard, 1964.

Santos, R. C. Teoria de preços na análise da riqueza de Quesnay. In: Estudos Econômicos, 26 (3), São Paulo: FEA-USP, 1996, pp. 44I-464.

"A construção do objeto teórico da Economia Política: Quesnay e Smith.” In: Economia, no 2I, Curitiba: UfPR, 1997, pp. I55-I82.

Sheehan, J. \& Wahrman, D. Invisible Hands. Self-organization and the Eighteenth Century. Chicago: The University of Chicago Press, 2015.

Smith, A. The Theory of Moral Sentiments (тмs). Oxford: Clarendon Press, i976a. An Inquiry into the Nature and Causes of the Wealth of the Nations (wN). Oxford: Clarendon Press, 1976b. . Essays on Philosophical Subjects (EPS), Oxford: Clarendon Press, I980. . Lectures on Jurisprudence (LJ). Oxford: Clarendon Press, 1978.

. Teoria dos sentimentos morais. (TSM) Trad. L. Luft. São Paulo: Martins Fontes, 1999.

. A riqueza das nações - Investigação sobre sua natureza e suas causas (RN).

Trad. L. J. Baraúna. São Paulo: Nova Cultural (col.: Os Economistas), 1996.

Steuart, J. An Inquiry into the Principles of Political Oeconomy (Ippo). Ed. A. Skinner. Chicago: The University of Chicago Press, 1966.

TuCKer, J. An Essay on the Advantages and Disadvantages which Respectively Attend France and Great Britain, with Regard to Trade. With Some Proposals for Removing the Principal Disadvantages of Great Britain. $3^{\text {rd }}$ edition. London: T. Trye, I753. 
Turgot, A. R. J. Oeuvres de Turgot et documents le concernant. Tomes I-V. (Jusqu'en 1761) Turgot étudiant et magistrat (от1). Ed. G. Schelle. Paris: Librairie Félix Alcan, I913-1923.

VAN DEN Berg, R. "Turgot's Valeurs et monnaies: our incomplete knowledge of an incomplete manuscript." In: Euro Journal of History of Economic Thought. v. 2I, n. 4, 20I4, pp. 549-582.

Waszek, N. The Scottish Enlightenment and Hegel's Account of 'Civil Society'. Dordrecht: Kluwer, 1988. 